\title{
Comparative efficiency of technologies for conversion and transportation of energy resources of Russia's eastern regions to NEA countries
}

\author{
Aleksandr Kler, Elina Tyurina*, Aleksandr Mednikov \\ Melentiev Energy Systems Institute of Siberian Branch of the Russian Academy of Sciences, 130, \\ Lermontov str., Irkutsk, 664033, Russia
}

\begin{abstract}
The paper presents perspective technologies for combined conversion of fossil fuels into synthetic liquid fuels and electricity. The comparative efficiency of various process flows of conversion and transportation of energy resources of Russia's east that are aimed at supplying electricity to remote consumers is presented. These also include process flows based on production of synthetic liquid fuel.
\end{abstract}

\section{Introduction}

There are considerable energy resources in the eastern regions of Russia, which make it possible both to meet domestic demand for energy carriers and to export them. However, the distances between regions that possess energy resources and potential consumption regions, first of all, in NEA countries, are great, which affects greatly the value of transportation costs. Therefore, the estimation of efficiency of long-distance transportation variants is getting topical. Since the share of gaseous and solid fuel in the energy balances is increasing the study on process flows of long-distance transportation of natural gas and coal energy, which include combination of technologies for conversion and transportation is of special interest [1-5].

Analysis of known technologies for conversion and transportation of energy carriers allows one to make the conclusion that the process flows including coal and gas conversion into synthetic liquid fuels (SLF) will be efficient for transmission of energy produced from gaseous and solid fuels at long distances. The benefit here will be achieved owing to the costs of liquid fuel transportation that are much lower than the costs of gaseous and solid fuel transportation. Besides, the costs of liquid fuel for consumers, first of all, power plants are much lower than those of coal consumers. At the same time, the process of SLF production is quite expensive. Therefore, it is necessary to estimate at what distance of transportation the additional SLF production costs will be recovered by saving the transportation costs [6$11]$.

*Corresponding author: tyurina@isem.irk.ru 
The paper aims to compare the process flows based on technologies for SLF production and conventional technologies for energy transportation (pipeline transportation of natural gas, railway transportation of coal, electricity transportation over DC transmission lines). There are grounds to believe that at a large-scale long-distance transportation of coal, natural gas or SLF their marginal consumers will be power plants. Therefore it is sensible to assume electricity price for remote consumers, to be determined on the basis of value of internal rate of return, equal for all variants, as a criterion of process flow efficiency.

\section{The plants for co-production of synfuels and electricity}

Among technologies for large-scale production of various SLFs the most promising is the technology for production of methanol from synthesis gas which is in turn produced from coal or natural gas. This relates to the fact that methanol production is a well-known heterocatalytic process: sufficiently selective, highly-productive and continuous. Methanol is suitable for transportation and storage [12]. The world's total methanol production capacityaccounts for about 45 million tons yearly.

It should be noted that methanol production is accompanied by release of a considerable amount of heat and formation of combustible blowdown gases. An efficient method for utilization of this "energy waste" is co-production of methanol and electricity at an integrated plant. These plants for co-production of synfuels and electricity are considered in this paper. Electricity produced by the plants is considered to be consumed in the area close to the plant. The price of this electricity is specified in the economic calculations.

The plants for co-production of synfuel and electricity are characterized by highly complicated flow charts and various physical and chemical processes that occur in their components. Besides, there is virtually no experience in their design. The research on the plants consists mainly of mathematical modeling and technical and economic studies on the models.

The works on mathematical modeling of the plants intended for synthesis of SLF and their technical and economic studies have been performed by the Energy Systems Institute of RAS for a long time [13-16]. Mathematical model of certain blocks of the plants on coal and natural gas, as well as the models of the whole plants were constructed. The studies made it possible to find optimal schemes and parameters, and identify the conditions for the plants to become economically efficient.

Fig.l shows as an example the calculated scheme of the plant for coal-based co-production of methanol and electricity. Conventionally the plant is represented by three blocks: block of synthesis gas production, block of catalytic synthesis of methanol and energy block.

In block I solid fuel is gasified and the mixture of hydrogen and carbon monoxide (synthesis gas) is produced. Besides, in this block synthesis gas is cooled in the system of gas generator heat exchangers and cleaned from ash and sulfur compounds, and CO2. Heat released in gas cooling is used for generation of steam that goes to steam turbine of energy block to produce electricity. In block II the catalytic synthesis of methanol is performed. This process is accompanied by generation of low pressure steam in intermediate heat exchangers of synthesis reactors that are intended for extraction of reaction heat. This steam goes to the low pressure section of the steam turbine. Blowdown gas goes from the block of synthesis to combustion chamber of gas turbine. The combustion products from the chamber are then used to generate electricity in gas turbines. In waste-heat boiler the steam of high and low pressure is generated. This steam goes to steam turbine for electricity generation.

It should be noted that the flow chart of the plant was developed on the basis of the most promising technologies of the processes that are employed in the plant. Fuel gasification takes place in gas generators with fluidized bed and dry slag removal, where steam-oxygen blast under the pressure of $2 \mathrm{MPa}$ is used. This gas generator is an analogue of rather well studied 
and commercially implemented gas generator Winkler. Gas generators of the kind are most often applied in the plants for synthesis of SLF. The optimal flow chart of methanol synthesis with direct- flow reactors of synthesis and intermediate cooling of synthesis products in heat exchangers by boiling water was chosen based on the preliminary studies of various technologies: with isothermal reactors, with preliminarily switched synthesis reactor, with cooling of synthesis products by fresh synthesis gas, etc. The steam and gas combined cycle, being the most promising for energy plants, is suggested for energy block.

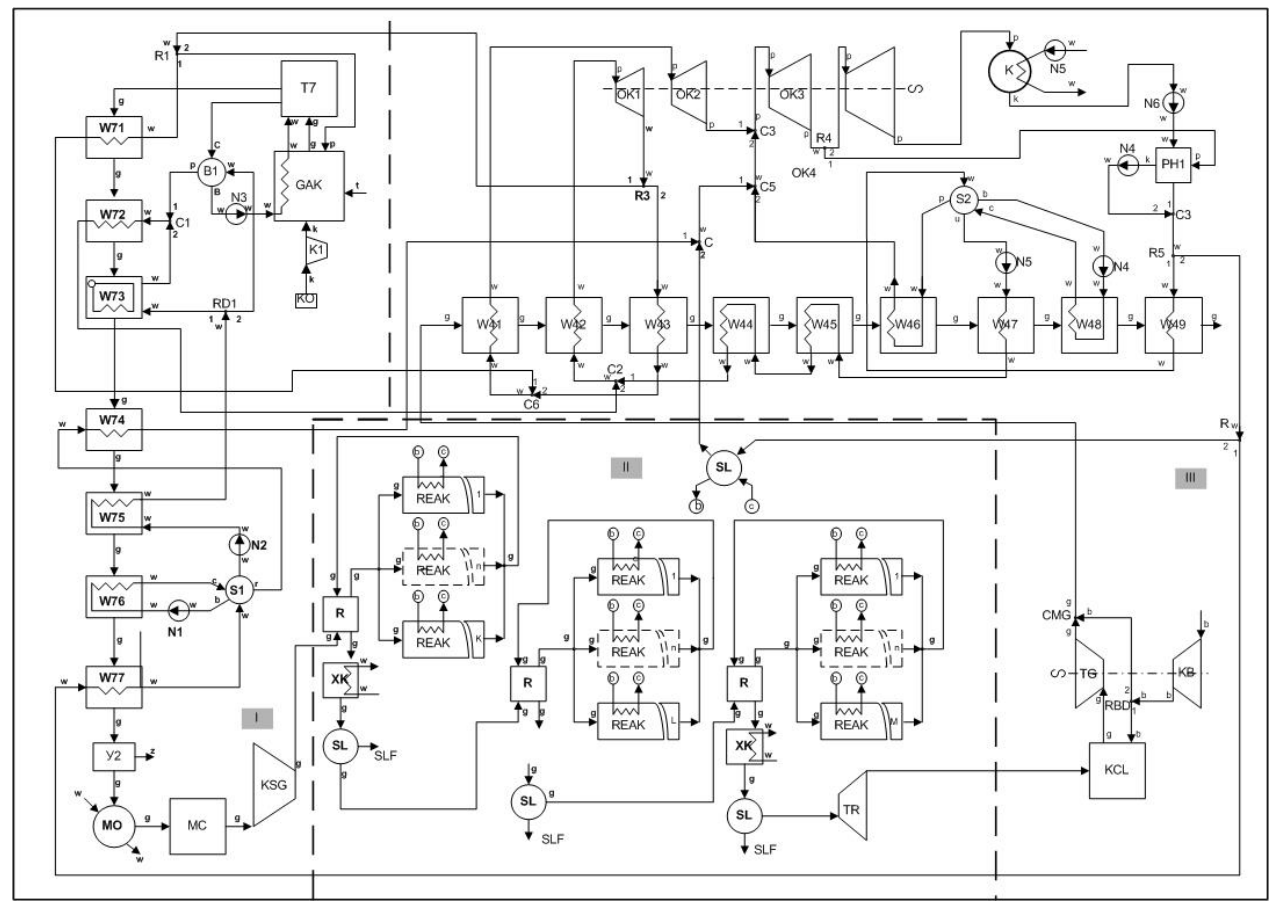

Fig. 1. Calculated scheme of a plant for coal-based methanol production: $\mathrm{T} 7$ - radiation heat exchanger on gasification products, GAK - gas generator, $\mathrm{KO}$ - block for oxygen production, $\mathrm{Kl}$ oxygen compressor, W71-W77 - convective heat exchanger on gasification products, B1, S1, S2, S3 - separator drum, C, C1-C6 - mixer of water or steam flows, R1-R5 - separator of water or steam flow, N1-N6 - pump, RD1 - fractional separator of water or steam, Y1, Y2 - dry ash collector, MO wet scrubber, $\mathrm{MC}$ - $\mathrm{CO} 2$ removal system, $\mathrm{KSG}$ - synthesis gas compressor, $\mathrm{R}$ - regenerative gas-gas heat exchanger, SL - separator, XK - condenser, REAK - adiabatic zone of SLF synthesis reactor, $\mathrm{TP}$ - expansion gas turbine. KCL - combustion chamber of gas turbine, TG - main gas turbine, KB air compressor, RBD - air stream separator. CMG - mixer of gas and air streams, OK1-OK4 - steam turbine compartments, W41-W49 - convective gas-water heat exchangers of waste-heat boiler. K steam turbine condenser, PHI - low pressure regenerative heater. Notation of flows: $\mathrm{t}-\mathrm{coal}, \mathrm{k}-$ oxygen, $\mathrm{p}$ - steam, $\mathrm{w}$ - water, steam, steam-water mixture, cooling water, $\mathrm{g}$ - conversion products, synthesis gas, blowdown gas, combustion products, b - air, kk - condensate, $\mathrm{u}, \mathrm{b}, \mathrm{c}$ - water supplied to circulating pump. 1,2 - bifurcation, mixing of flows. I - block of synthesis gas production, II block of methanol synthesis. III - energy block.

The flow chart of the plant for co-production of methanol and electricity (PCME) on the basis of natural gas is similar to that presented above, except for the block for natural gas conversion, in which natural gas converter is used instead of gas generator on coal to produce synthesis gas.

Studies of the PCME aim to determine optimal parameters of the plants and change of their technical and economic performance depending on operation conditions (prices of fuel, 
equipment and products). The studies take into consideration the most important factor that influences the cost of all blocks of the plant and its energy efficiency, i.e. relationship between production of synthetic liquid fuel and electricity. The major parameters that determine this relationship include composition of blast supplied to gas generators on coal or natural gas converters, the number of reactors at synthesis stages, etc. These parameters were among the variables to be optimized in the study of the plant. Optimization of the plant included solving the problems of nonlinear mathematical programming which implies finding the plant parameters (composition of blast supplied to gas generators, catalyst volumes in reactors of synthesis, temperatures and pressures of working media of the combined cycle plant, etc.) that provide minimum value of the SLF price at set levels of internal rate of return (IRR) and prices of fuel consumed and electricity supplied, in terms of physical and technical constraints on the plant parameters.

Table 1 presents major technical and economic parameters of optimal variants of the plant for synthesis of methanol on the basis of coal and gas that were obtained from optimization studies on mathematical models of the plants.

Table 1. Main technical and economic parameters of optimal variants of PCME.

\begin{tabular}{|l|c|c|}
\hline \multirow{2}{*}{ Parameter, unit } & \multicolumn{2}{c|}{ PCME variants } \\
\cline { 2 - 3 } & on gas & on coal \\
\hline Annual consumption of natural fuel, million m ${ }^{3}$, thousand tons & 2200 & 4500 \\
\hline Annual consumption of reference fuel, thousand tce & 2500 & 2500 \\
\hline Annual methanol production: & 1400 & 1350 \\
- in reference fuel, thousand tce & 1900 & 1880 \\
- in natural fuel, thousand tons & 330 & 270 \\
\hline Capacity, MW: & 160 & 145 \\
- steam turbine & 167 & 185 \\
- gas turbine & 320 & 225 \\
Auxiliary power & 2200 & 1560 \\
\hline Useful power & 66,8 & 61,7 \\
\hline Annual electricity output, million kWh & 720 & 990 \\
\hline Exergy efficiency. \% & 192 & 220 \\
\hline Capital investments in the plant, million USD & & \\
\hline SLF price (IRR=15\%), USD/tce & & \\
\hline
\end{tabular}

\section{Process flows of electricity supply to remote consumers, on the basis of natural gas and coal energy}

The considered plants for methanol synthesis were included in the process flows of electricity supply to remote consumers, on the basis of energy of natural gas and coal (brown coal) of large deposits. 2):

The following process flows of energy production and transportation were compared (Fig.

1. Natural gas production, $1420 \mathrm{~mm}$ gas pipeline, electricity production by gas combined -cycle plants (GP 1420). 
2. Natural gas production, methanol production at PCME, methanol transportation by the $1220 \mathrm{~mm}$ pipeline, electricity production from methanol at combined cycle plant (PCMEg+PL 1120).

3. Coal production, methanol production at PCME, methanol transportation by the 1220 $\mathrm{mm}$ pipeline, methanol-based electricity production at combined cycle plant (PCMEc+PL 1220).

4. Coal production, railway transportation of coal from production site to consumers, coal-based electricity production by environmentally friendly thermal power plants (RWc+TPPc).

5. Coal production, electricity production from coal on production site by environmentally friendly TPPs, electricity transportation to consumers along DC transmission lines (TPPc+DCTL).

6. Natural gas production, electricity production from gas on production site by environmentally friendly TPPs, electricity transportation to consumers along DC transmission lines (TPPg+DCTL).

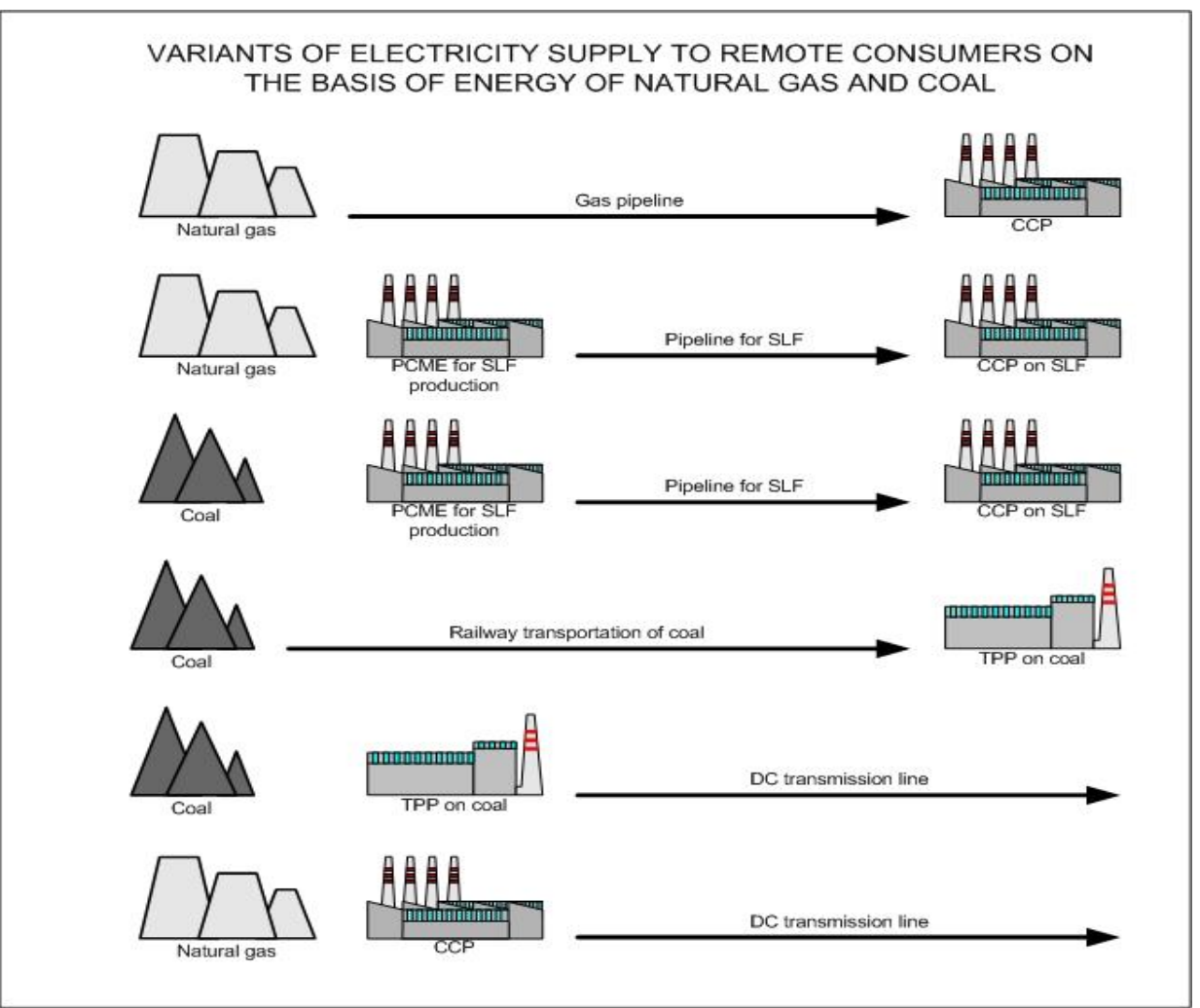

Fig. 2. The considered variants are characterized by the following features.

The economic efficiency of the indicated process flows is compared by the criterion of minimum electricity cost for consumers (at the given profitability level). A generalized statement of the optimization problem has the form:

$$
\left.\min _{C_{e l}, C_{t}, I R R_{z}} C_{e l} K^{T P P}, K^{P C M E}, K^{t r}, U^{T P P}, U^{P C M E}, U^{t r}, C_{t}\right),
$$

subject to 


$$
\begin{gathered}
H(x, y, s) \geq 0, \\
G(x, y, s) \geq 0, \\
\operatorname{IRR}\left(K^{T P P}, K^{P C M E}, K^{t r}, U^{T P P}, U^{P C M E}, U^{t r}, C_{t}\right)=I R R_{z},
\end{gathered}
$$

where $C_{e l}$ - electricity price at the process flow outlet; $C_{t}$ - natural gas or coal price; $x-$ a vector of independent variables of energy transport system; $y-$ a vector of calculated parameters; $s-$ a vector of initial technical and economic data; $I R R_{z}$ - a set value of internal rate of return; $H-$ a vector function of equality constraints; $G-$ a vector function of inequality constraints; $K^{T P P}$ - capital investments in electricity production; $K^{P C M E}$ - capital investment in conversion; $K^{t r}$ - capital investment in transport; $U^{T P P}$ - costs for electricity production; $U^{P C M E}$ - costs for conversion; $U^{t r}$ - costs for transport depending on electricity supply variant.

Environmentally clean TPPs with the net efficiency $45 \%$ are used for electricity production from coal, combined-cycle plants with the net efficiency $52 \%$ are taken for electricity production from natural gas [17]. Natural gas and coal are converted into methanol at PCMEs. Electricity from methanol is produced at combined-cycle plants on methanol with the efficiency $55 \%$. Natural gas is transported by the $1420 \mathrm{~mm}$ pipeline. The $1220 \mathrm{~mm}$ pipeline was suggested for methanol transport over long distances. Unit costs for methanol transport by the $1220 \mathrm{~mm}$ pipeline and natural gas transport by the $1420 \mathrm{~mm}$ pipeline were obtained by optimization calculations at the previous stages and amount to $\$ 10 /$ tce per thousand $\mathrm{km}$ for methanol and $\$ 28 /$ thousand $\mathrm{m}^{3}$ per thousand $\mathrm{km}$ for gas pipelines [14-16]. Unit costs for railway coal transport are taken in accordance with the tariff directory of JSC "RZhD" [18]. They make up \$7.6-9.5/tons per thousand km. The price of coal in situ is taken equal to $\$ 30 /$ tce, that of gas $-\$ 50 /$ thousand $\mathrm{m}^{3}$. The $\pm 500 \mathrm{kV}$ single circuit transmission lines with a rated capacity of $3000 \mathrm{MW}$ were designed for DC transmission. Unit costs for electricity transmission by DC lines were also obtained at the previous stages of studies and make up $1 \mathrm{cent} / \mathrm{kWh}$ per thousand $\mathrm{km}$. The main initial data applied in calculations are presented in Tables $2-4$. The data concerning a plant for co-production of methanol and electricity are taken based on Table 1.

The results of comparing the economic efficiency of the mentioned process flows by the criterion of minimum electricity cost for consumers are given in Fig. 3.

Note that the $1220 \mathrm{~mm}$ methanol pipelines allow pumping of about 100 million tce. Such amount of fuel can produce some 400 billion $\mathrm{kWh}$ of electricity. Electricity transmission by the $\pm 500 \mathrm{kV}$ DC transmission lines of a rated capacity of $3000 \mathrm{MW}$ allows delivery of about 20 billion $\mathrm{kWh}$ to consumers annually.

Table 2. Assumed technical and economic characteristics of dc transmission line.

\begin{tabular}{|l|c|}
\hline \multicolumn{1}{|c|}{ Parameter, unit } & Value \\
\hline Specific investment in overhead TL, thousand doll./km & 230 \\
\hline Specific investment in converter substation, doll./kW & 85 \\
\hline Energy losses at converter substations, $\%$ & 2 \\
\hline Total section of wires with the same pole, $\mathrm{mm}^{2}$ & 2800 \\
\hline
\end{tabular}




\begin{tabular}{|l|c|}
\hline $\begin{array}{l}\text { Annual energy losses in overhead line at rated output power and number of } \\
\text { utilization hours, \% /thousand km }\end{array}$ & 3,75 \\
\hline Rated output power, MW & 3000 \\
\hline Capacity utilization per year, h & 6000 \\
\hline Capital investment in infrastructure, million doll. & 80 \\
\hline $\begin{array}{l}\text { Operating costs, \% of investment } \\
\text { - coverhead line }\end{array}$ & 0,8 \\
\hline $\begin{array}{l}\text { Depreciation charges. \% of investment } \\
2\end{array}$ \\
\hline
\end{tabular}

Table 3. Assumed indices of gas (GP) and methanol (MP) pipelines.

\begin{tabular}{|c|c|c|}
\hline Parameter, unit & GP & MP \\
\hline Rated pressure, $\mathrm{MPa}$ & 7,4 & 5,4 \\
\hline Rated capacity utilization per year, $\mathrm{h}$ & 8000 & 8000 \\
\hline $\begin{array}{l}\text { Volume of pumped medium, gas - billion } \mathrm{m}^{3} \text {. methanol - million } \\
\text { tce }\end{array}$ & 36 & 100. \\
\hline Base unit cost of linear part, million doll./km & 2,7 & 1,63 \\
\hline Fixed component of investment in pumping station, million doll. & 25 & 15 \\
\hline Variable component of investment in pumping station, doll./kW & 400 & 700 \\
\hline $\begin{array}{l}\text { Specific fuel consumption by gas driven turbine at compressor } \\
\text { stations of pipelines. gce } / \mathrm{kWh}\end{array}$ & 384 & - \\
\hline $\begin{array}{l}\text { Electricity price of electric drive of pumping stations at methanol } \\
\text { pipelines. cent } / \mathrm{kWh}\end{array}$ & - & 5 \\
\hline $\begin{array}{l}\text { Rated low calorific value of natural gas or methanol. } \mathrm{MJ} / \mathrm{nm}^{3} \text {. } \\
\mathrm{MJ} / \mathrm{kg}\end{array}$ & 33,5 & 21,1 \\
\hline Operating costs. $\%$ of investment & 3,5 & 3,5 \\
\hline Depreciation charges. $\%$ of investment & 6 & 6 \\
\hline Cost of pumping, gas - doll./m3, methanol - doll./tce & 28 & 10 \\
\hline
\end{tabular}


Table 4. Assumed technical and economic indices of TPPs.

\begin{tabular}{|l|c|c|c|}
\hline \multicolumn{1}{|c|}{ Parameter, unit } & $\begin{array}{c}\text { CCP on } \\
\text { SLF }\end{array}$ & CCP on gas & $\begin{array}{c}\text { TPP on } \\
\text { coal }\end{array}$ \\
\hline Specific investment per unit of useful power. doll./kW & 700 & 700 & 1400 \\
\hline Specific consumption of equivalent fuel (net), tce/kWh & 223 & 236 & 275 \\
\hline Conditionally fixed costs, \% of investment & $3-4$ & $3-4$ & $4-5$ \\
\hline Depreciation charges, \% of investment & $4-6$ & $4-6$ & $5-7$ \\
\hline Installed capacity utilization, h & 6000 & 6000 & 6000 \\
\hline
\end{tabular}

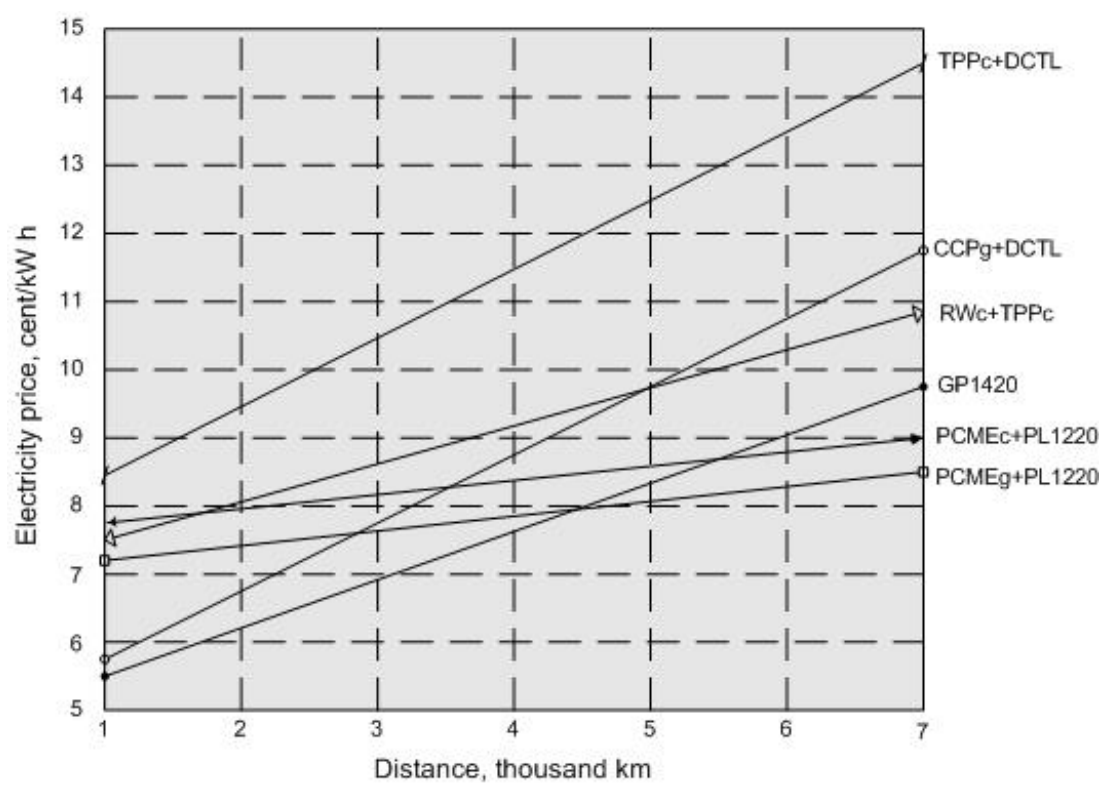

Fig. 3. Results of comparing the efficiency of variants for electricity supply to remote consumers.

\section{Conclusions}

Fig. 3 shows that transportation of natural gas by the $1420 \mathrm{~mm}$ pipeline is economically efficient over distances to 4,5 thousand $\mathrm{km}$. For larger distances it is rational to use a PCME for natural gas conversion into SLF and transport it by a pipeline. Transport of (brown) coal by railway is reasonable over distances to about 1,7 thousand $\mathrm{km}$. For larger distances it is advisable to transport SLF produced from coal by pipelines. Note that the tariff for coal transport by railway that is applied in calculations is accepted based on the current tariff policy of JSC "RZhD". The tariffs formed do not take into account capital investment in construction of new railways. It is expected that considerable volumes of coal transported 
can lead to limitation of capacity of operating railways and the necessity will arise to construct new branches. As a result the tariffs for coal transport will rise sizably.

Electricity transmission by DC transmission lines that is produced from brown coal or natural gas can not compete with distant piped large-scale transport of liquid and gaseous fuel.

Hence, it can be asserted with a high degree of validity that the process flows based on PCME for conversion of solid and gaseous fuel into SLF with its further piped transportation over large distances are most efficient as compared to other methods of distant transportation of energy of these fuel kinds.

\section{Acknowledgements}

This work was carried out at Melentiev Energy Systems Institute of Siberian Branch of the Russian Academy of Sciences and supported by Russian Science Foundation via grant № 16$19-10174$.

\section{References}

1. Y. Xia, Y. Jin, K.P. Chen, M. Chen, D. Chen, J. of Nat. Gas Sci. and Eng., 41, 112-124 (2017)

2. A. Vatansever, Energy Policy, 108, 1-11 (2017)

3. W.Mazyan, A.Ahmadi, H.Ahmed, M.Hoorfar, J. of Nat. Gas Sci. and Eng., 30, 487-514 (2016)

4. D.A. Wood, Ch. Nwaoha, B.F. Towler, J. of Nat. Gas Sci. and Eng., 9, 196-208 (2012)

5. D. Osborne, The Coal Handbook: Towards Cleaner Production (WPL, 2013)

6. S. Yang, Z. Liu, Z. Tang, Yi. Wang, Q. Chen, Yu. Sun, Energy Conve. and Manage., 150, 375-381 (2017)

7. A. Bassani, G. Bozzano, C. Pirola, E. Ranzi, S. Pierucci, F. Manenti, Energy Procedia, 105, 4519-4524 (2017)

8. A. Śliwińska, D. Burchart-Korol, A.Smoliński, Sci. Total Environ., 574, 1571-1579 (2017)

9. H.Huang, H.Xiao, S. Yang, App. Therm. Eng., 125, 891-903 (2017)

10. T. Blumberg, T. Morosuk, G. Tsatsaronis, Energy. (to be published)

11. X. Liu, J. Liang, D. Xiang, S. Yang, Y. Qian, J. of Cleaner Production, 129, 53-64 (2016)

12. C. Zhang, K. Jun, G. Kwak, Y. Lee, H. Park, J. of CO2 Utilization, 16, 1-7 (2016)

13. A.M. Kler, E.A. Tyurina, Mathematical modeling and technical and economic studies on plants for coproduction of methanol and electricity for methanol synthesis. (Novosibirsk, Nauka. 1998) (In Russian)

14. A.M. Kler, B.G. Saneev, A.D. Sokolov, E.A. Tyurina, J. Energetika, 2, 36-43 (2000) (In Russian)

15. A.M. Kler, B.G. Saneev, A.D. Sokolov, E.A. Tyurina, J. Energy perspectives, 6, 53-60 (2002) (In Russian)

16. A.M. Kler, E.A. Tyurina, J. Energy perspectives, 9, 69-78 (2005) (In Russian)

17. Reference calculation of transportation cost. http://rpp.rzd.ru/Rzd/

18. O.N. Favorsky., V.L. Polishchuk, I.M. Livshits, V.I. Dlugoselsky, J. Therm. Eng., 9, 4651 (2007) 